\title{
MODELLING GROUND MOTION IN THE HUTT VALLEY, NEW ZEALAND
}

\section{Shu Qin $\mathrm{Ma}^{1}$, Martha Savage ${ }^{2}$ and Jiashun $\mathrm{Yu}^{3}$}

\begin{abstract}
The Hutt Valley is an alluvial basin that hosts the city of Lower Hutt, in the North Island, New Zealand. The basin is bounded by the Wellington Fault on its northwest side, and exhibits ground motion amplification factors up to about 15, measured by several seismic experiments using weak motion and portable seismic arrays during 1990-1991. Synthetic seismograms computed by using local 1D stratigraphic models under each station reproduce qualitatively the amplitudes and durations of the corresponding observed seismograms at most of the soft site stations of the arrays. Amplification factors estimated from spectral ratios of the synthetic seismograms are up to about 9 . The authors present comparisons of amplification between synthetics and observations, allowing a "calibration" of the model so that it could be used to determine more realistic ground amplifications for earthquake scenarios.
\end{abstract}

\section{INTRODUCTION}

It is well known that surface geology strongly influences the ground motion of a region, in the event of an earthquake. Such influence, regarded as "site effects" by earthquake engineers and strong motion seismologists, has been studied in the last 30 years, in terms of parameters that best characterize ground motion, such as peak values (acceleration, velocity and displacement), and the input seismic wavefield. For example, within the broad classification of a site into soil and rock, it is well established that soft sediments deposited over bedrock can amplify the ground motion significantly for frequencies up to a value between 10 and $15 \mathrm{~Hz}$, depending on the types of soil and rock (Adams et al., 2003; Benites and Olsen, 2005). To study site effects, researchers have used direct observations either from strong motion networks (Kawashima et al., 1986) or seismic experiments (Taber and Smith, 1992), and numerical modelling (Ma, 2004; Benites and Olsen, 2005). For generalities, the reader is referred to Hays and Gori (1983).

New Zealand, and particularly the Wellington region, has provided the scene for several studies of site effects. Taber and Smith (1992) deployed 24 seismographs in Hutt Valley to study the frequency dependent response of all soil types, among which five were on firm sites, and 19 were on soft sites. Amplification factors of up to 15 have been estimated from spectral ratios of weak motion of soil sites compared to firm sites, in the frequency range $2-5 \mathrm{~Hz}$ (Taber and Smith, 1992; Sritharan and McVerry, 1992).

The characterization of site effects requires a shaking model that can show, within relatively small error, the main features of the observed ground motion. This characterization is crucial for further prediction of the ground motion using earthquake scenarios.

One of the first efforts to model the ground motion in the Lower Hutt area was made by Adams et al. (2003). They developed a 2-D profile across the valley, using the Finite Element Method with a mesh size of approximate $1 \mathrm{~m}$. They modelled up to $5 \mathrm{~Hz}$ and found the modelled ground motion was amplified most greatly at the sites that were within the valley about 100-300 $\mathrm{m}$ away from the basin edge. They attributed that phenomenon to the basin edge effect (Kawase, 1996).

\footnotetext{
1 Geosciences Department, University of Houston, Houston, Texas 77204-5007, USA

2 Institute of Geophysics, Victoria University of Wellington, Box 600, Wellington, New Zealand

3 Institute of Geological and Nuclear Sciences, Box 30368, Lower Hutt, New Zealand
} 
In recent years a 3-D digital model of the Wellington-Lower Hutt area built from the integration of geological borehole profiles, seismic experiments and gravity data has been produced in order to predict the ground motion due to earthquake scenarios on the Wellington Fault, using a Finite Difference scheme (Benites and Olsen, 2005). The prediction is limited to frequencies lower than $1.5 \mathrm{~Hz}$, and the modelled peak velocity was located in Wellington Harbour, with a value of $3.1 \mathrm{~m} / \mathrm{s}$ (Benites and Olsen, 2005). The modelled ground motions in Wellington Harbour and Hutt Valley decayed more slowly than in surrounding regions due to amplification in their thick sedimentary basins. Sediments increase seismic shaking ground motion significantly (Seed et al., 1988; Hartzell et al., 1997; Nagano, 1998).

3-D modelling is time consuming and expensive to use to characterize high frequencies. While full 3-D modelling is needed to fully characterize the ground motion, much of the effect of sediments on the seismograms may be caused by local sediment thickness that can be modelled with 1-D amplification (Lay and Wallace, 1995; Coutel and Mora, 1998; Ma, 2004).

In this paper, we try to reproduce some of the characteristics of ground motion amplification on sediment sites with local $1 \mathrm{D}$ models, using the discrete wave number method. We try to determine to what extent a 1-D local profile underneath a site characterizes the corresponding local site effects in the Lower Hutt area. To do that, we compute synthetic seismograms at each of the recording sites of the Taber and Smith (1992) weak motion experiment, using the discrete wave number synthesis of Bouchon and Aki (1977) combined with the generalized reflection/transmission coefficients of Kennett (1983). The 1-D local profiles were derived from the Wellington 3D models (Benites and Olsen, 2005).

\section{DATA}

\subsection{Seismic data in Lower Hutt}

The dataset from the portable deployment in Lower Hutt of Taber and Smith (1992) is used. The sites extended $10 \mathrm{~km}$ up the valley from the Petone foreshore (Figure 1). Twenty two instruments were placed in the Hutt Valley region between November 1990 and February 1991, with two additional sites in Wainuiomata (Figure 1). Five sites were located on the sides of the valley on firm soil or bedrock. Three-component digital seismographs were installed in the study areas, running at a sampling rate of $100 \mathrm{~Hz}$. The sites were chosen to sample the full range of soil types and depths in the region, from bedrock to thick flexible sediments. Only those earthquakes that were recorded at most sites and whose focal mechanisms might therefore be well resolved were chosen (Table 1). The events selected ranged in magnitude from 3.2 to 5.7 and were between $23 \mathrm{~km}$ and $285 \mathrm{~km}$ from station L14 of the array. The events were in the focal depth range of $8 \mathrm{~km}$ to $104 \mathrm{~km}$.

The weak-motion reference site for Lower Hutt array, L14, was located on weathered bedrock. The sites will be discussed in terms of their classification within the seismic hazard microzoning scheme of Van Dissen et al. (1992) (Figure 1), who divided Lower Hutt into 5 zones based on the geology and measured response to strong and weak seismic shaking. Zone 1 is underlain by bedrock or weathered bedrock, Zone 2 is typically underlain by compact alluvial and fan gravel, Zones 3-4 are underlain to a depth of $20 \mathrm{~m}$ by interfingered layers of flexible sediment and compact gravel and sand, and Zone 5 is generally underlain by more than $10 \mathrm{~m}$ of flexible sediment of low shear-wave velocity.

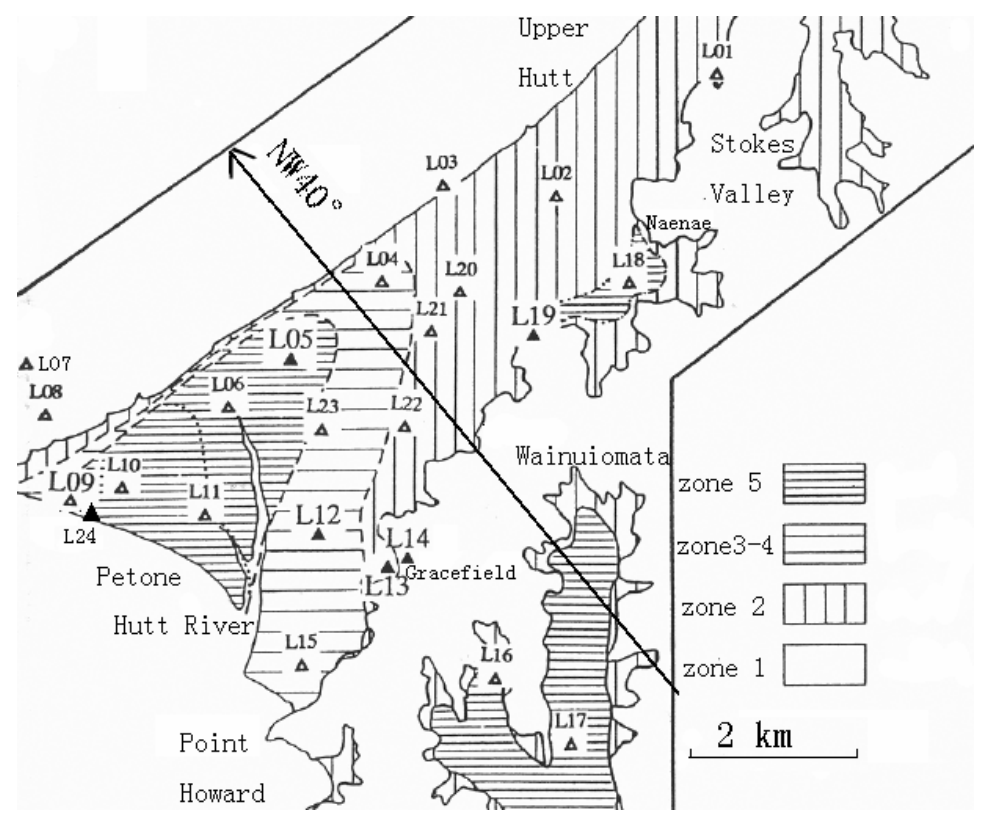

Figure 1: Locations of Recording Sites in Lower Hutt Deployment of Taber and Smith (1992) plotted on the ground shaking hazard map of Van Dissen et al. (1992). 
Table 1. Earthquakes recorded in Lower Hutt deployment

\begin{tabular}{|c|c|c|c|c|c|c|c|c|c|c|}
\hline $\begin{array}{c}\text { Event } \\
\text { No. }\end{array}$ & Date & Time & $\begin{array}{c}\text { Lat } \\
\left({ }^{\circ}\right)\end{array}$ & $\begin{array}{c}\text { Long } \\
\left(^{\circ}\right)\end{array}$ & $\begin{array}{c}\text { Depth } \\
(\mathbf{k m})\end{array}$ & Mag & $\begin{array}{c}\text { strike } \\
\left(^{\circ}\right)\end{array}$ & $\begin{array}{c}\text { Dip } \\
\left({ }^{\circ}\right)\end{array}$ & $\begin{array}{c}\text { Rake } \\
\left({ }^{\circ}\right)\end{array}$ & $\begin{array}{l}\text { Dist } \\
(\mathbf{k m})\end{array}$ \\
\hline 1 & 29/11/90 & $14: 54$ & -39.80 & 174.55 & 104.4 & 4.3 & 55 & 80 & 245 & 144 \\
\hline 2 & 29/11/90 & 23:05 & -40.69 & 174.66 & 58.9 & 4.5 & 235 & 40 & 315 & 64 \\
\hline 3 & $30 / 11 / 90$ & $17: 38$ & -40.73 & 174.95 & 16.1 & 4.0 & 15 & 20 & 105 & 56 \\
\hline 4 & $16 / 12 / 90$ & $14: 54$ & -41.14 & 175.16 & 33.0 & 3.2 & 45 & 65 & 300 & 23 \\
\hline 5 & 29/12/90 & $10: 49$ & -41.31 & 174.11 & 48.6 & 3.7 & 60 & 45 & 300 & 68 \\
\hline 6 & 09/01/91 & $15: 50$ & -41.06 & 174.73 & 59.9 & 3.6 & 100 & 20 & 170 & 25 \\
\hline 7 & 28/01/91 & $12: 58$ & -41.89 & 171.61 & 8.3 & 5.7 & 300 & 50 & 345 & 285 \\
\hline
\end{tabular}

*distance from L14.

Figure 2 is a plot of the seismograms recorded in the Hutt Valley for an earthquake at $144 \mathrm{~km}$ distance for a line of sites trending roughly across the valley. The smallest amplitude response is visible at sites L07 and L08 located on rock on the west side of the valley, and on L13 at the east end of the valley. The initial amplitude of the shaking at the sites in the valley (L05, L06, L10, L12, and L15) is similar or only slightly larger than at the rock sites but the shaking continues much longer at the valley sites. L01 was actually on basement (Figure 1), but its shaking looks like that of a basin site, probably because it is close to the basin edge. The two sites in Wainuiomata (L16 and L17) show much greater amplification of the shaking as well as increased duration.

\subsection{Focal mechanisms}

The focal mechanisms of the events (Table 1; Figure 3) were determined by the amplitude ratio method (Schwartz, 1995; Matcham et al., 2006), with the seismic data from New Zealand Standard Network and using the Wellington 1D velocity model (Robinson, 1986).

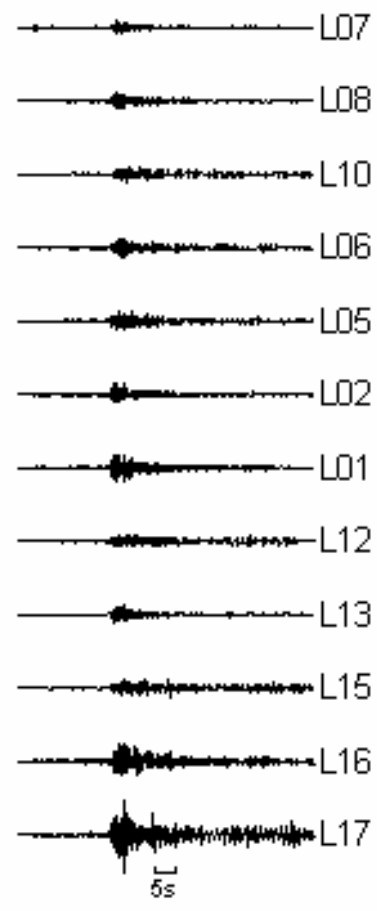

(a) NS component

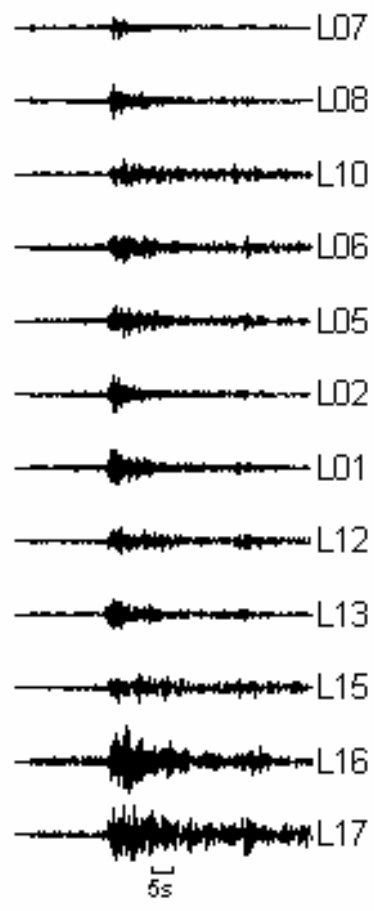

(b) Evio' component

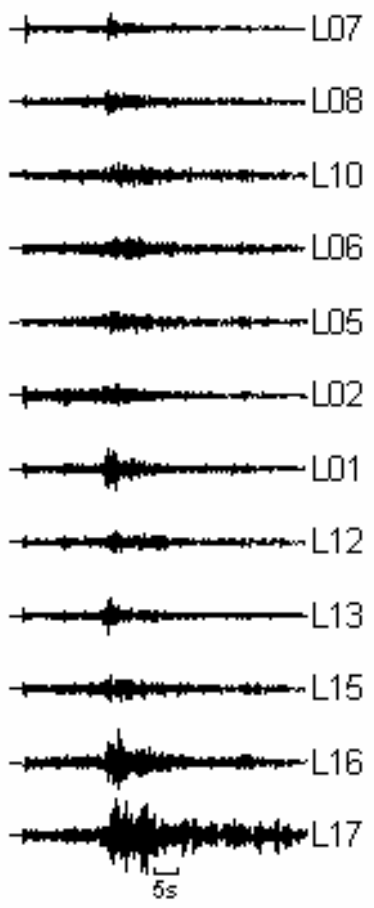

(c) UD component

Figure 2: Seismograms of event 1 (Table 1) displayed in a roughly NW40 ${ }^{\circ}$ line across the Hutt Valley from L07 (rock site used as a reference) to Petone (L10) to Gracefield (L13) to Wainuiomata (L16 and L17, flexible sediment sites). Traces are all normalized by $0.8 \mathrm{~mm} / \mathrm{s}$, the peak ground velocity of L17. L14 and L19 failed to record this event. 


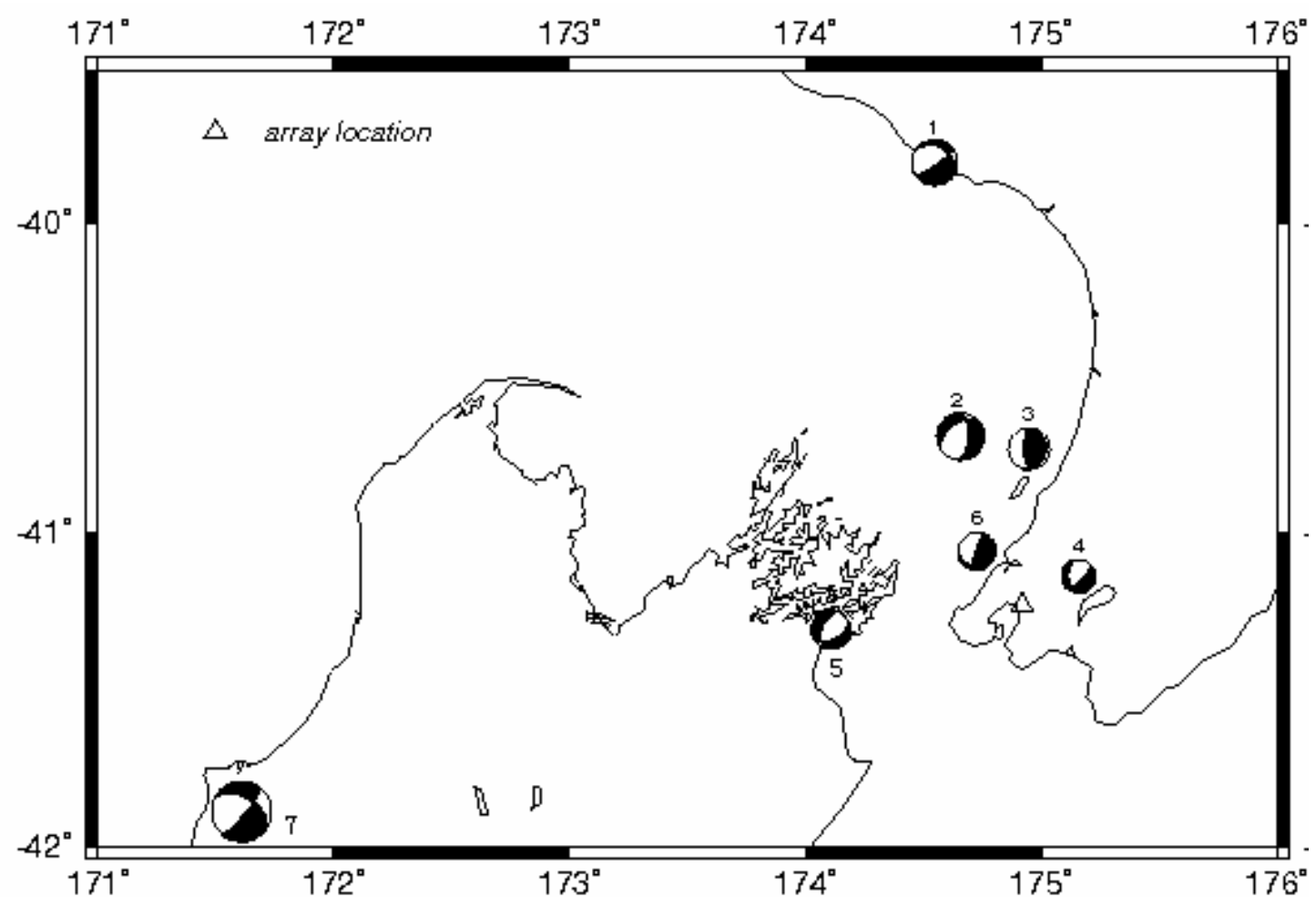

Figure 3: Results of the focal mechanism determination represented as lower hemisphere stereographic projections at the epicenter locations. The shaded quadrants are compression zones. The number by the focal mechanism is the event number (Table 1). The radii of the circles are proportional to their magnitudes.

\section{LOCAL 1D MODELS}

The local 1D models are shown in Tables 2(a) and 2(b). The values of the elastic parameters for Layer 1 to Layer 5 in Tables 2(a) and 2(b) are obtained from the Wellington 3D model (Benites and Olsen, 2005); those for Layer 6 to Layer 11 are obtained from the Wellington 1D model (Robinson, 1986).

Table 2(a). Local crustal models (Benites and Olsen, 2005; Robinson, 1986) underneath each station of the Lower Hutt deployment. The layer number increases with depth.

\begin{tabular}{|l|l|l|l|l|l|l|l|l|l|l|l|}
\hline $\begin{array}{c}\text { Elastic } \\
\text { Parameter }\end{array}$ & \multicolumn{1}{|c|}{$\begin{array}{c}\mathbf{1} \\
\mathrm{N}\end{array}$} & $\mathbf{2}$ & $\mathbf{3}$ & $\mathbf{4}$ & $\mathbf{5}$ & $\mathbf{6}$ & $\mathbf{7}$ & $\mathbf{8}$ & $\mathbf{9}$ & $\mathbf{1 0}$ & $\mathbf{1}$ \\
\hline $\mathrm{v}_{\mathrm{p}}(\mathrm{km} / \mathrm{s})$ & 0.30 & 0.52 & 0.57 & 0.87 & 2.60 & 5.63 & 5.77 & 6.39 & 6.79 & 8.07 & 8.77 \\
\hline $\mathrm{v}_{\mathrm{s}}(\mathrm{km} / \mathrm{s})$ & 0.175 & 0.3 & 0.33 & 0.5 & 1.5 & 3.16 & 3.49 & 3.50 & 3.92 & 4.80 & 4.86 \\
\hline dens $\left(\mathrm{g} / \mathrm{cm}^{3}\right)$ & 1.75 & 1.80 & 1.85 & 1.90 & 2.26 & 2.61 & 2.69 & 2.76 & 2.93 & 3.39 & 3.35 \\
\hline
\end{tabular}

Among all the local 1D models, site L09 has the thickest soft sediments, with a thickness of $0.32 \mathrm{~km}$. Site L17 has the thickest top sediment layer (thickness of $0.166 \mathrm{~km}$ ). L10 was located at the seaward end of the Lower Hutt Valley, and L17 in the Wainuiomata valley (Figure 1). Seven sites (L03, L07,
L08, L14, L16 and L19) are modelled as firm soil, i.e. with no soft sediments underneath them*. L01, L19, L14 and L16 are located to the south east of Hutt Valley. L03, L07 and L08 are located towards the north west of Hutt Valley (Figure 1). 
Table 2(b). Layer thickness (Benites and Olsen, 2005; Robinson, 1986) in each local crustal model underneath each station of the Lower Hutt deployment. The layer number increases with depth. The thicknesses of the top 5 layers all add up to $1 \mathrm{~km}$. L01(3) denotes that L01 recorded three among all the seven events (Table 1). The others are analogous.

\begin{tabular}{|c|c|c|c|c|c|c|c|c|c|c|}
\hline $\begin{array}{l}\text { Station } \\
\text { Name }\end{array}$ & $\begin{array}{l}\text { Layer } \\
1 \mathrm{~km})\end{array}$ & $\begin{array}{l}\text { Layer } \\
2(\mathrm{~km}) \\
\end{array}$ & $\begin{array}{l}\text { Layer } \\
3(\mathbf{k m}) \\
\end{array}$ & $\begin{array}{l}\text { Layer } \\
4(\mathrm{~km})\end{array}$ & $\begin{array}{l}\text { Layer } \\
5(\mathrm{~km})\end{array}$ & $\begin{array}{l}\text { Layer } \\
6(\mathrm{~km})\end{array}$ & $\begin{array}{l}\text { Layer } \\
7(\mathbf{k m})\end{array}$ & $\begin{array}{l}\text { Layer } \\
8 \mathrm{~km})\end{array}$ & $\begin{array}{l}\text { Layer } \\
9(\mathrm{~km})\end{array}$ & $\begin{array}{c}\text { Layer } \\
10(\mathrm{~km})\end{array}$ \\
\hline L01(3) & 0 & 0 & 0 & 0 & 1.0 & 4 & 10 & 10 & 10 & 10 \\
\hline L02(5) & 0.022 & 0.002 & 0.091 & 0 & 0.885 & 4 & 10 & 10 & 10 & 10 \\
\hline L03(2) & 0 & 0 & 0 & 0 & 1.0 & 4 & 10 & 10 & 10 & 10 \\
\hline L04(6) & 0.024 & 0.003 & 0.028 & 0.169 & 0.776 & 4 & 10 & 10 & 10 & 10 \\
\hline L05(4) & 0.022 & 0.002 & 0.053 & 0.173 & 0.75 & 4 & 10 & 10 & 10 & 10 \\
\hline L06(6) & 0.025 & 0.009 & 0.055 & 0.214 & 0.697 & 4 & 10 & 10 & 10 & 10 \\
\hline L07(4) & 0 & 0 & 0 & 0 & 1.0 & 4 & 10 & 10 & 10 & 10 \\
\hline L08(6) & 0 & 0 & 0 & 0 & 1.0 & 4 & 10 & 10 & 10 & 10 \\
\hline L09(2) & 0.036 & 0.012 & 0.057 & 0.215 & 0.68 & 4 & 10 & 10 & 10 & 10 \\
\hline L10(3) & 0.031 & 0.003 & 0.071 & 0.201 & 0.678 & 4 & 10 & 10 & 10 & 10 \\
\hline L11(6) & 0.022 & 0.014 & 0.062 & 0.206 & 0.696 & 4 & 10 & 10 & 10 & 10 \\
\hline L12(3) & 0.020 & 0.004 & 0.042 & 0.129 & 0.805 & 4 & 10 & 10 & 10 & 10 \\
\hline L13(3) & 0.005 & 0 & 0 & 0 & 0.995 & 4 & 10 & 10 & 10 & 10 \\
\hline L14(5) & 0 & 0 & 0 & 0 & 1.0 & 4 & 10 & 10 & 10 & 10 \\
\hline L15(4) & 0.025 & 0.015 & 0.032 & 0.001 & 0.927 & 4 & 10 & 10 & 10 & 10 \\
\hline L16*(5) & 0 & 0 & 0 & 0 & 1.0 & 4 & 10 & 10 & 10 & 10 \\
\hline L17(3) & 0.166 & 0 & 0 & 0 & 0.834 & 4 & 10 & 10 & 10 & 10 \\
\hline L18(2) & 0.033 & 0.002 & 0.025 & 0 & 0.95 & 4 & 10 & 10 & 10 & 10 \\
\hline L19(2) & 0 & 0 & 0 & 0 & 1.0 & 4 & 10 & 10 & 10 & 10 \\
\hline L20(2) & 0.019 & 0.020 & 0.006 & 0.083 & 0.872 & 4 & 10 & 10 & 10 & 10 \\
\hline L21(2) & 0.019 & 0.013 & 0.012 & 0.141 & 0.815 & 4 & 10 & 10 & 10 & 10 \\
\hline L22(2) & 0.013 & 0.002 & 0.033 & 0.038 & 0.914 & 4 & 10 & 10 & 10 & 10 \\
\hline $\mathrm{L} 23(2)$ & 0.020 & 0 & 0.055 & 0.169 & 0.756 & 4 & 10 & 10 & 10 & 10 \\
\hline L24(1) & 0.035 & 0.002 & 0.071 & 0.191 & 0.701 & 4 & 10 & 10 & 10 & 10 \\
\hline
\end{tabular}

* L16 was actually on sediment near the edge of the basin, but the local 1D model of L16 (Table 2 (b)) derived from Wellington 3D model (Benites and Olsen, 2005) is firm, probably due to a slight mismatch in the smoothed model edge compared to the real basin edge. The local 1D model was based on the latitude and longitude of the station from Taber and Smith (1992) and those of the starting point of the Wellington 3D model (Benites and Olsen, 2005).

\section{MODELLING}

A modulated ramp ( Ben-Menahem and Singh , 1981 ) is used as the source time function to compute the particle velocity:

$$
g(t)=\left\{\begin{array}{cl}
0 & t<0 \\
\frac{1-\cos \omega t}{T} & 0 \leq t \leq T \\
0 & t>T
\end{array}\right.
$$

where $\omega=\frac{2 \pi}{T} ; T$ is known as the rise time.
We calculate the $1 \mathrm{D}$ synthetic seismograms of all the events with the corresponding focal mechanisms (Table 1).

Variation of elastic parameters between stations is limited to the top $1 \mathrm{~km}$ of the models (Tables 2 (a) and (b)). The effects of sediment layers on the synthetic waveforms can be observed in Figure 4. The amplitude and duration of the synthetic seismograms for soft sites L17, L15, L12 and L10 are much greater than those for firm sites L08 and L07. The large amplitudes and duration at L17, L15, L12 and L10 demonstrate the effects of resonance, whose frequency is determined by both the thickness and S-wave velocity of the top thin layers. 


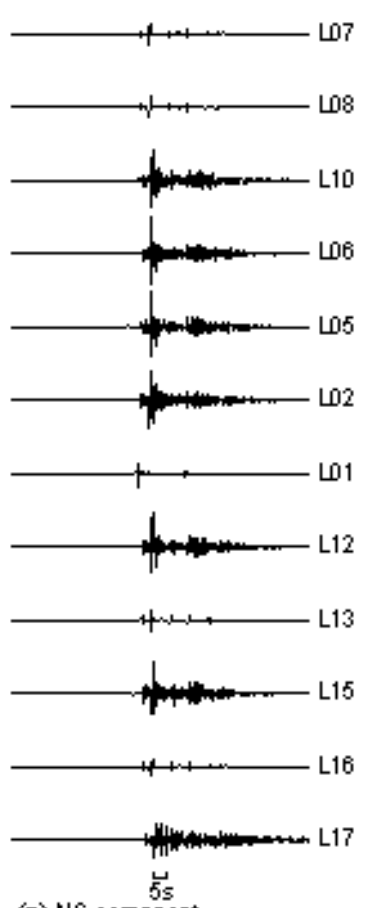

(a) NS compnent

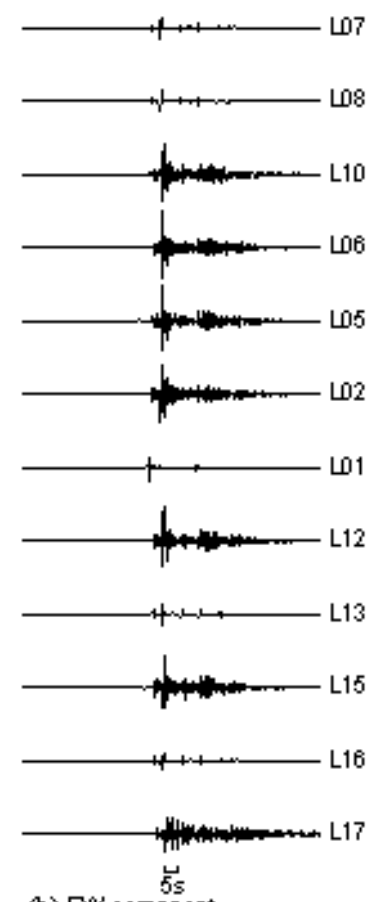

(b) ENo' compnent

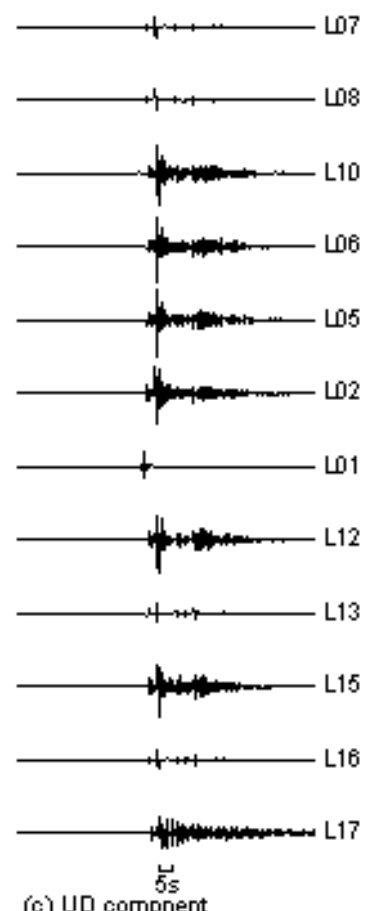

(c) UD compnent

Figure 4: Synthetic seismograms of event 1 (Table 1), displayed approximately across the NW40 ${ }^{\circ}$ valley profile. Each trace is normalized by the maximum amplitude of the trace in the column, which is actually (a) L17, (b) L06 and (c) L05. L07 serves as the reference site in this event.
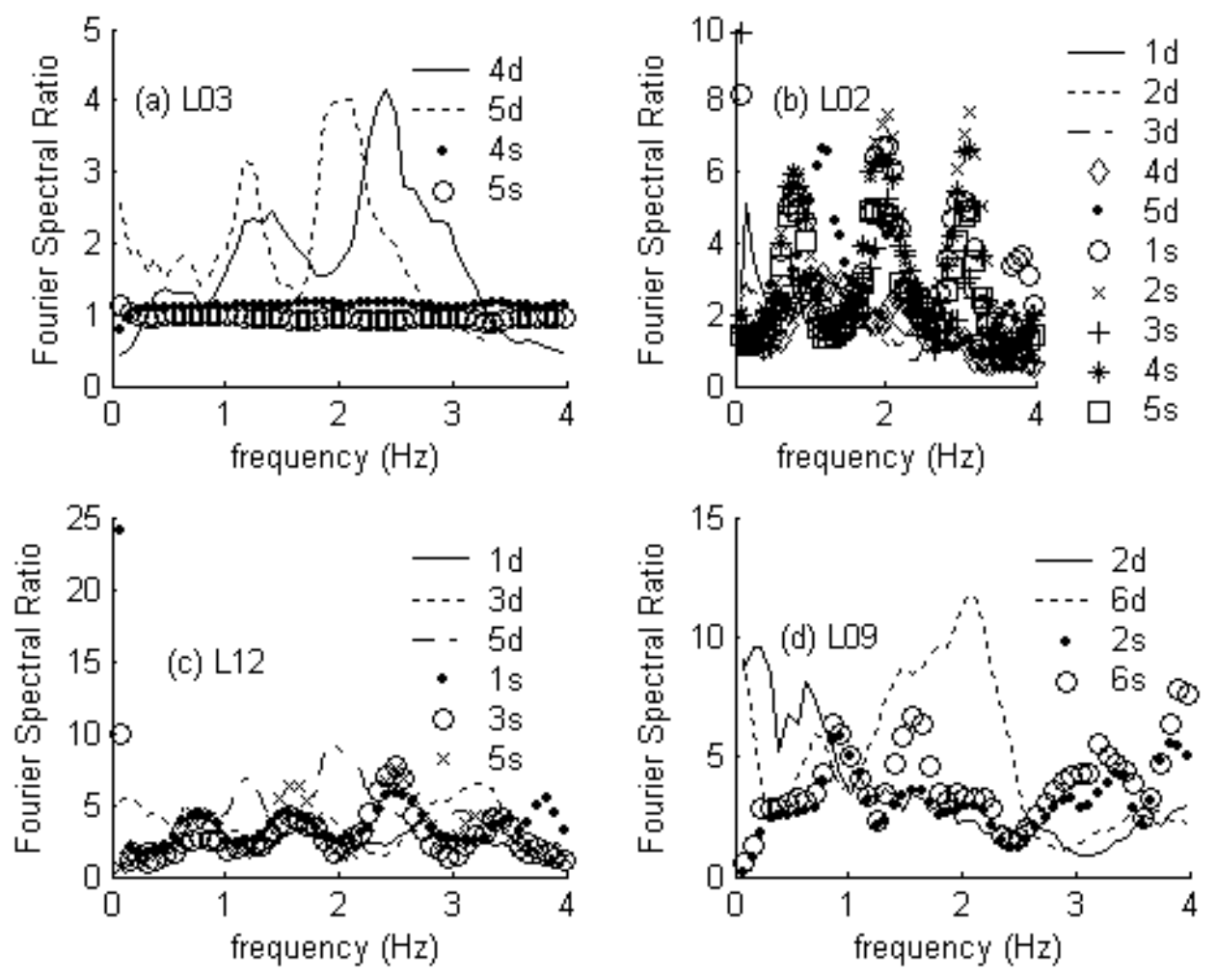

Figure 5: Comparison between Fourier spectral ratio of data and synthetics in the horizontal components for all recorded events for site L03, L02, L12 and L09. '4d' and '4s' represent Fourier spectral ratios of the data and synthetic, respectively, for event 4 [Table 1]. Other symbols are analogous. Out of 7 events, L03 and L09 recorded 2 only, L02 recorded 5, and $L 12$ recorded 3. 
The parameters of layer 5 (Table 2(a)) have been obtained from Benites and Olsen (2005). The simple translation of this model into the Robinson (1986) model results in a physically unrealistic strong impedance between layers 5 and 6 , which produced a significant $S P$ conversion evident in the seismograms (Figure 4). However, this does not affect the spectral ratios because layers 5 and 6 exist, with the same parameters, in all models for both soil and reference sites.

Comparing Figure 4 with Figure 1, we see that 1D modelling can reproduce some characteristic of soft layering, e. g., peak ground velocity amplification and the enhancement of duration of the ground motion in soft sites compared to the rock sites.

\section{COMPARISON OF FOURIER SPECTRAL RATIOS BETWEEN DATA AND SYNTHETICS}

The Fourier spectrum $U(a)$ at each site is the product of three factors (Borcherdt and Glassmoyer, 1992):

$$
U(a)=S(a) P(a) B(a)
$$

where $S(a)$ represents the spectrum of the source, $P(a)$, the spectrum of the path from the source to Hutt Valley basement, and $B(\boldsymbol{a})$, the spectrum of the sediment layers. $\mathrm{S}(a)$ is a constant for all the sites for a given earthquake. $P(a)$ can be considered the same for all sites, because the spatial extent of the array is small compared with the focal distance. Only $B(a)$ changes drastically from site to site. Therefore the spectral ratios reflect the variations between sites, i.e., the site effects.

For each earthquake, we calculated the Fourier spectral ratio for each site relative to a reference site, for the observed data and the synthetic seismograms, separately. A Fourier spectral ratio is strongly influenced by the duration of the shaking and its peak amplitude is generally larger than the peak velocity ratio over the time history. This is particularly true for resonant sites when the whole Hutt Valley shakes like a harmonic oscillator. For example, for event 1 (Table 1) at site

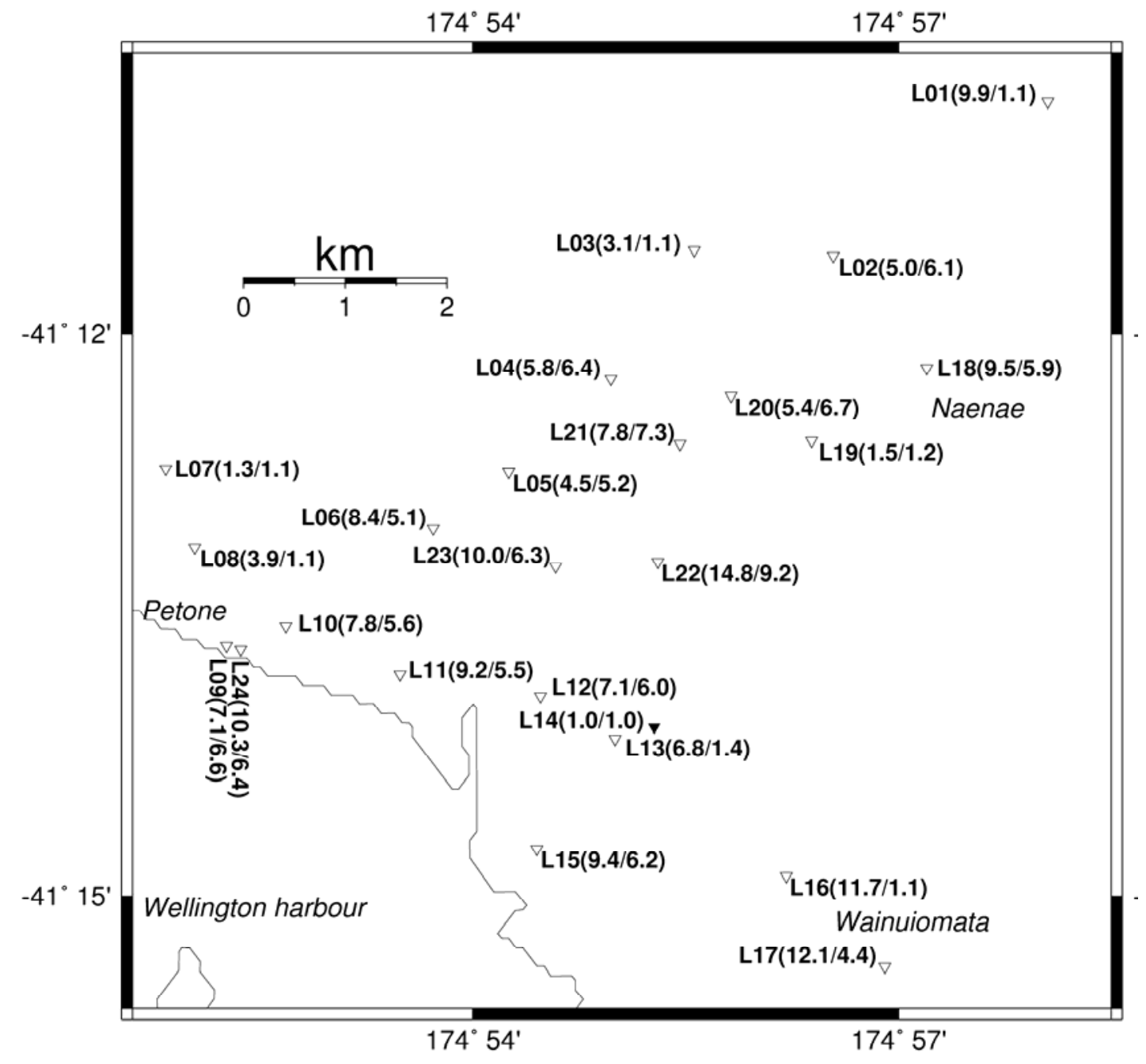

Figure 6: Distribution map of peak Fourier spectral ratios. Each peak ratio is an average of the peak ratio values of all recorded earthquakes. The pair of values for each site is presented in the format of data/synthetics. L14, marked by a solid triangle on the map, is the usual reference site. Thus the Fourier spectral ratio is 1 for L14 by definition. 
L17, the peak Fourier spectral ratio was 12.1 whereas the ratio of peak ground velocity was only 2.0. All the cycles of moderate motion as shown in the seismic traces in Figure 1 may excite resonances in buildings with the same period. This is why Fourier spectral ratio is chosen to characterize site effects instead of peak velocity ratio.

A $0.4 \mathrm{~Hz}$ triangular window was first employed to smooth the Fourier spectral amplitudes. Then a Fourier spectral ratio was obtained by dividing each amplitude spectrum by the corresponding spectrum from a reference site. L14 is a firm bedrock site and was the first choice as a reference in this study. The site, used in a larger scale regional study, exhibited a de-amplification effect (Yu and Haines, 2003). However this should be negligible as our study is limited to the effects due to the local sediment in the Hutt Valley. If L14 failed to record an event, firm site L19 or L07 was used as reference.

Fourier spectral ratios, of the data and 1D synthetics at four sites, are illustrated in Figure 5. The four sites, L03, L02, L12 and L09 are from, and hence represent zone 1, zone 2, zones 3-4 and zone 5, respectively. The average Fourier spectral ratios for the data at site L03 are up to 3 times larger than those for the synthetics, which are close to 1 . This suggests that the site effect or basin edge effect in L03 has not been accounted for by the 1D modelling. However, as expected, generally the amplification increases from zone 1 to zone 5 for both data and synthetics. The spatial distribution of spectral ratios from both observations and $1 \mathrm{D}$ modelling are shown in Figure 6.

\section{CALIBRATION}

In this section, we determine "calibration factors" for synthetic seismograms to match the true motion of the ground. Two types of calibration factors are required, for the calibrations of the time history and the Fourier spectrum, separately, of a synthetic recording. It is desired that the calibration will bring the synthetics to match the observed data in terms of peak values either in the time domain or in the frequency domain. To define the calibration factors that will serve the purposes, we first define the peak amplification factor $r$ over the time history of the velocity recording $(v)$ for a soil site as:

$$
\begin{aligned}
& r_{x, i j}^{d} \equiv \frac{\max \left(\left|v_{x, i j}^{d}(t)\right|\right)}{\max \left(\left|v_{x, i_{0} j}^{d}(t)\right|\right)} \\
& r_{x, i j}^{s} \equiv \frac{\max \left(\left|v_{x, i j}^{s}(t)\right|\right)}{\max \left(\left|v_{x, i_{0} j}^{s}(t)\right|\right)}
\end{aligned}
$$

where superscripts $d$ and $s$ distinguish whether the velocity recording $v$ is observed data $(d)$ or synthetic data (s); subscript variable $x$ takes one of the three components values: $n$ for the north-south component, $e$ for the east-west component, and, $u$ for the up-down component; subscripts $i$ and $j$ stand for the $i^{\text {th }}$ site and the $j^{\text {th }}$ event, and $i_{0}$ is a reference site, i.e., L14, L19 or L07 in the lower Hutt deployment. $\max (\bullet)$ applies over the entire effective time $(t)$ domain. Hence $r_{x, i j}^{d}$ is the peak amplification factor for the $x$ component time history of the $j^{\text {th }}$ event observed at the $i^{\text {th }}$ site.

Similarly, the peak amplification factors for the Fourier spectra are defined as follows

$$
\begin{aligned}
& R_{x, i j}^{d}=\max \left[\frac{V_{x, i j}^{d}(f)}{V_{x, i_{0} j}^{d}(f)}\right] \\
& R_{x, i j}^{s}=\max \left[\frac{V_{x, i j}^{s}(f)}{V_{x, i_{0} j}^{s}(f)}\right]
\end{aligned}
$$

where $V(f)$ is the amplitude Fourier spectrum of the time history $v(t) . \max (\bullet)$ here applies to an effective frequency band between 0.4 to $4.0 \mathrm{~Hz}$.

Using these peak amplification factors we can now define the calibration factors $C_{x}$ and $C_{x}$ for the calibrations of the time history and the Fourier Spectra of the synthetic seismograms:

$$
\begin{gathered}
C_{x}=\frac{1}{m}\left[\sum_{j=1}^{m} \frac{1}{n}\left(\sum_{i=1}^{n} \frac{r_{x, i j}^{d}}{r_{x, i j}^{s}}\right)\right] \\
C_{x}=\frac{1}{m}\left[\sum_{j=1}^{m} \frac{1}{n}\left(\sum_{i=1}^{n} \frac{R_{x, i j}^{d}}{R_{x, i j}^{s}}\right)\right]
\end{gathered}
$$

where $n$ is the total number of stations that recorded the event in each corresponding area in Figure 1, $m$ is the total number of events recorded.

Listed in Table 3 are the calibration factors calculated using the synthetics and the observed data according to definitions (3) to (8), averaged over the zones. A factor greater than 1.0 implies that the data are larger in amplitude than the $1 \mathrm{D}$ synthetics; vice versa for a factor less than 1.0. The factors in Table 3 show that most 1D synthetics slightly underestimate the peak velocity ratios, but all underestimate the peak spectral ratios. The calibration factor is used by simply multiplying the synthetic recording by the calibration factor. This should bring the synthetics to a best fit with the data in terms of its peak amplification. 
Table 3. Calibration factors and standard deviations for the local 1D models by zone. Zone 1(6) denotes that 6 recording sites were in Zone 1. The others are analogous.

\begin{tabular}{|c|c|c|c|c|}
\hline Factors & Zone 1(6) & Zone 2(5) & Zone 3-4(4) & Zone 5(9) \\
\hline$C_{n}$ & $1.7 \pm 0.4$ & $1.2 \pm 0.1$ & $0.8 \pm 0.2$ & $1.1 \pm 0.2$ \\
\hline$C_{e}$ & $1.9 \pm 0.2$ & $0.90 \pm 0.2$ & $0.6 \pm 0.1$ & $0.7 \pm 0.1$ \\
\hline$C_{u}$ & $1.9 \pm 0.3$ & $1.1 \pm 0.1$ & $0.7 \pm 0.1$ & $1.1 \pm 0.2$ \\
\hline$C_{n}$ & $4.5 \pm 0.6$ & $3.1 \pm 0.3$ & $2.1 \pm 0.1$ & $3.8 \pm 0.2$ \\
\hline$C_{e}$ & $6.0 \pm 0.4$ & $2.0 \pm 0.2$ & $1.6 \pm 0.2$ & $2.9 \pm 0.2$ \\
\hline$C_{u}$ & $4.4 \pm 0.3$ & $2.6 \pm 0.2$ & $1.8 \pm 0.1$ & $5.8 \pm 0.2$ \\
\hline
\end{tabular}

*The site classification can be found in Figure 1.

Note that events 1 and 7 (Table 1) are far from Wellington; they fall beyond the region of validity of the Wellington velocity models (Tables 2(a) and (b)). This may lead to a distortion of synthetic seismograms for events 1 and 7 compared to real data. However, the major difference in response between the stations is still most likely to come from the near-station structure, and hence the calibration factors in Table 3 should still be good to first order.

\section{$7 \quad$ CONCLUSIONS}

From our analysis and comparison of 1D synthetic with the observational data, we conclude the following:

1D modelling simulates, qualitatively, the observed peak ground motion amplification and shaking duration increase on the sediment sites, in the Lower Hutt area. At the sites (L01, L03, L13 and L16) near the Hutt Valley basin edge, synthetic seismograms from 1D modelling hardly match the observed ground motion. However, generally, spectral ratios from the 1D synthetics underestimate the ground motion amplification compared to those from the recorded data (Figure 6). The observed Fourier amplitude amplification ranges from 1 to 14.8, while that of the $1 \mathrm{D}$ synthetics ranges from 1 to 9.2 . This is likely due to valley confinement, while $1 \mathrm{D}$ models do not capture.

The authors have presented calibration factors (Table 3) that can be used with the Wellington-Hutt Valley model to predict ground motion in future earthquakes as follows: for a given location of interest, a one-dimensional earth model can be extracted from the Wellington-Hutt Valley model (Benites and Olsen, 2005), and synthetic seismograms can be calculated for it. To determine the expected ground motion, the spectral ratios should be calculated and calibrated using the factors listed in Table 3.

\section{ACKNOWLEDGMENTS}

Thanks are due to Dr. John Taber for providing the seismic data used in this study. Comments, suggestions, criticisms and corrections from Drs. Rafael Benites, Euan Smith and John Louie improved this manuscript greatly. The computer for modelling was provided by Victoria University of Wellington, New Zealand. Mr. Ralph Wahrlich offered technical support in using that computer. This study was funded by New Zealand Earthquake Commission, project number 01/462.

\section{REFERENCES}

Adams, B.M., Osborne, N. and Taber J.J. (2003), "Basin Edge Effect from Weak Ground Motions Across the Fault Bounded Edge of the Lower Hutt Valley, New Zealand", Bulletin of the Seismological Society of America; 93(6): 2703-2716.

Benites, R. and Olsen, K.B. (2005), "Modelling Strong Ground Motion in the Wellington Metropolitan area, New Zealand”, Bull. Seismol. Soc. Am.; 95(6): 2180-2196.

Ben-Menahem, A. and Singh, S.J. (1981), "Seismic waves and sources”, Springer-Verlag, New York, USA, 1108 pp.

Borcherdt, R.D. and Glassmoyer, G. (1992), “On the characteristics of local geology and their influence on ground motions generated by the Loma Prieta earthquake in the San Francisco Bay region, California”, Bull. Seimol. Soc. Amer;; 82: 603-641.

Bouchon, M. and Aki, K.(1977), "Discrete wavenumber representation of seismic source wave fields”, Bull. Seismol. Soc. Am.; 67: 259-277. 
Coutel, F. and Mora, P. (1998), "Simulation-based comparison of four site-response estimation techniques”, Bull. Seismol. Soc. Am.; 88: 30-42.

Hays, W.W. and Gori, P.L. (1983), “A Workshop on The 1886 Charleston, South Carolina, Earthquake and Its Implications for Today”, USGS, Open-File Report 83-843.

Hartzell, S., Cranswick, E., Frankel, A., Carver, F. and Mermonte, M. (1997),"Variability of site response in the Los Angeles Urban area”, Bull. Seismol. Soc. Am.; 87: 1377-1400.

Kawase, H., (1996). “The cause of the damage belt in Kobe: 'the basin edge effect', constructive interference of the direct S-wave with the basin induced diffracted Rayleigh waves", Seis. Research Lett.; 67: 25-34.

Kawashima, K., Aizawa, K. and Takahashi, K. (1986), "Attenuation of peak ground acceleration, velocity and displacement based on multiple regression analysis of Japanese strong motion records", Earthquake Engineering and Structural Dynamics; 14: 199-215.

Kennett, B.L.N. (1983), "Seismic Wave Propagation in Stratified Media, Cambridge Monographs on Mechanics and Applied Mathematics”, Cambridge University Press, Cambridge, UK, 342 pp.

Lay, T. and Wallace, T. (1995), Modern Global Seismology, Academic Press, San Diego, USA, 521 pp.

Ma, S.Q. (2004), “Calibration of Wellington 3D model”, MSc thesis, Institute of Geophysics, Victoria University of Wellington, New Zealand, 163 pp.

Matcham, I., Savage, M.K., Taber, J.J. and Reyners, M.E. (2006), "Earthquake source mechanism analysis for events between 1992 and 1997 using sparse New Zealand broadband data”. New Zealand Journal of Geology and Geophysics, 49(1): 75-89.
Nagano, M. (1998), “Amplification characteristics of the ground motions in deep irregular underground structure with vertical discontinuity”, Proc. 2nd Intl. Symposium on the Effects of Surface Geology on Seismic Ground Motion, Yokohama, Japan: 859-866.

Robinson, R. (1986), "Seismicity, structure and tectonics of the Wellington region, New Zealand”, Geophys. J. R. Astr. Soc.; 87: 379-409.

Schwartz, S.Y. (1995), "Source parameters of aftershock of the 1991 Costa Rica and 1992 Cape Mendocino, California earthquake from inversion of local amplitude ratio and broadband waveforms", Bull. Seismol. Soc. Am.; 85: 1560-1575.

Seed, H.B., Romo, M.P., Sun, J.I., Jaime, A. and Lysmer, J. (1988), "The Mexico earthquake of September 19, 1985-relationship between soil conditions and earthquake ground motions”, Earthquake Spectra; 4.

Sritharan, S. and McVerry, G.H. (1992), "Microzone effects in the Hutt Valley in records from a strong motion accelerograph array”, Bull. of the New Zealand National Society for Earthquake Engineering; 25: 246-264.

Van Dissen, R.J., Taber, J.J., Stephenson, W.R., Sritharan, S., Read, S.A.L, McVerry, G.H., Dellow, G.D. and Barker, P.R. (1992), "Earthquake ground shaking hazard assessment for the Lower Hutt and Porirua areas", Bull. of the New Zealand National Society for Earthquake Engineering; 25: 286-302.

Taber, J.J. and Smith, E.G.C. (1992), "Frequency dependent amplification of weak ground motions in Porirua and Lower Hutt, New Zealand", Bull. of the New Zealand National Society for Earthquake Engineering; 25(4): 303-331.

Yu, J. and Haines, J. (2003), “The choice of reference sites for seismic ground motion amplification analysis: case study at Parkway, New Zealand”. Bull. Seismol. Soc. Am., 93(2): 713-723. 